ROCZNIKI PSYCHOLOGICZNE/ANNALS OF PSYCHOLOGY

2019, XXII, 3, 257-276

DOI: http://dx.doi.org/10.18290/rpsych.2019.22.3-4

MONIKA A. KOZŁOWSKA

University of Wrocław, Poland

Institute of Psychology

\title{
RELATIONS BETWEEN SELF-ESTEEM DIMENSIONS AND FUNDAMENTAL SOCIAL MOTIVES
}

\begin{abstract}
The article presents the concept of fundamental social motives, which is novel for Polish readers, and its relations with self-esteem. The studies conducted so far suggest that there may be significant correlations between various dimensions of self-esteem and fundamental motives focused on interpersonal relations (affiliation motives and mate acquisition/retention motives). Data was collected from a sample of $N=363$ subjects in order to find predictors for the level and stability of self-esteem. The results include correlations between 11 scales measuring fundamental motives and self-esteem dimensions: its level and instability. Multiple regression analyses with self-esteem measures as explained variables and motives related to sociometer theory as explanatory variables were also conducted. The article presents a detailed discussion of regression analysis results for male and female samples. Limitations and future research directions are also discussed.
\end{abstract}

Keywords: fundamental social motives; self-esteem level; self-esteem instability.

The concept of fundamental social motives was proposed by Kenrick, Griskevicius, Neuberg, and Schaller (2010). In their recent publications they define it as referring to systems shaped by evolutionary mechanisms in order to select, organize, and initiate appropriate behaviors in order to cope with recurring social challenges and opportunities for reproduction (Neel, Kenrick, White, \& Neuberg, 2016). It is particularly important to stress that, in evolutionary psychology, the understanding of motivation is not restricted to behavior that serves reproduction. Human reproductive success depends on the ability to provide conditions for safe development and functioning in society for oneself and one's offspring.

Corresponding author: MoniKa A. KozŁowska-University of Wrocław, Institute of Psychology, ul. Dawida 1, 50-529 Wrocław, Poland; e-mail: monika.kozlowska2@uwr.edu.pl 
Whether the offspring reaches reproductive age is dependent on appropriate care provided by parents and other relatives. Such care means reducing the risk of contact with hazardous stimuli (including other people and potentially dangerous diseases) as well as strengthening social ties in order to obtain a variety of benefits. This understanding of reproductive success is reflected in a set of motives considered fundamental.

The model of fundamental social motives is distinguished from other concepts by the fact that it emphasizes the role of motivation in responding effectively to the challenges of interpersonal interactions. Unlike concepts identifying sets of motives (or needs) on the basis of phenomenological consequences for the subject (e.g., happiness, health, or meaning), the concept of fundamental motives, developed in the field of evolutionary psychology, identifies motives on the basis of their function in the process of gene promotion (Beall \& Tracy, 2017). The domains of social functioning discussed by Kenrick and colleagues (2010) are: physiological needs, self-protection, affiliation, status, mate attraction, mate retention, and kin care. The original version of the concept is based on Maslow's model of the hierarchical organization of motives, with physiological needs at the base of the hierarchy, followed by safety (the self-protection motive) and respect (status). The hierarchy of fundamental social motives differs from Maslow's model - it does not include the need for self-fulfillment. The authors explain that it is possible to satisfy this need through the realization of motives related to status and relationship with the mating partner. Another modification is related to the developmental perspective and the life history theory framework: at the top of the hierarchy there are the motives of searching for a partner, maintaining a partner, and parenthood. Moreover, all motives included in this model overlap and are not placed on top of one another (as was the case in Maslow's model).

This structure reflects the assumption that motives appearing at earlier stages of development are not replaced by objectives related to subsequent stages. With the emergence of new motives, all existing ones continue to direct human behavior to the extent that it is related to the person's specific characteristics and to direct stimuli present in the environment. It is assumed that the activation of each of the motives influences both behavioral and cognitive functioning of the individual (Kenrick, Neuberg, Griskevicius, Becker, \& Schaller, 2010). 


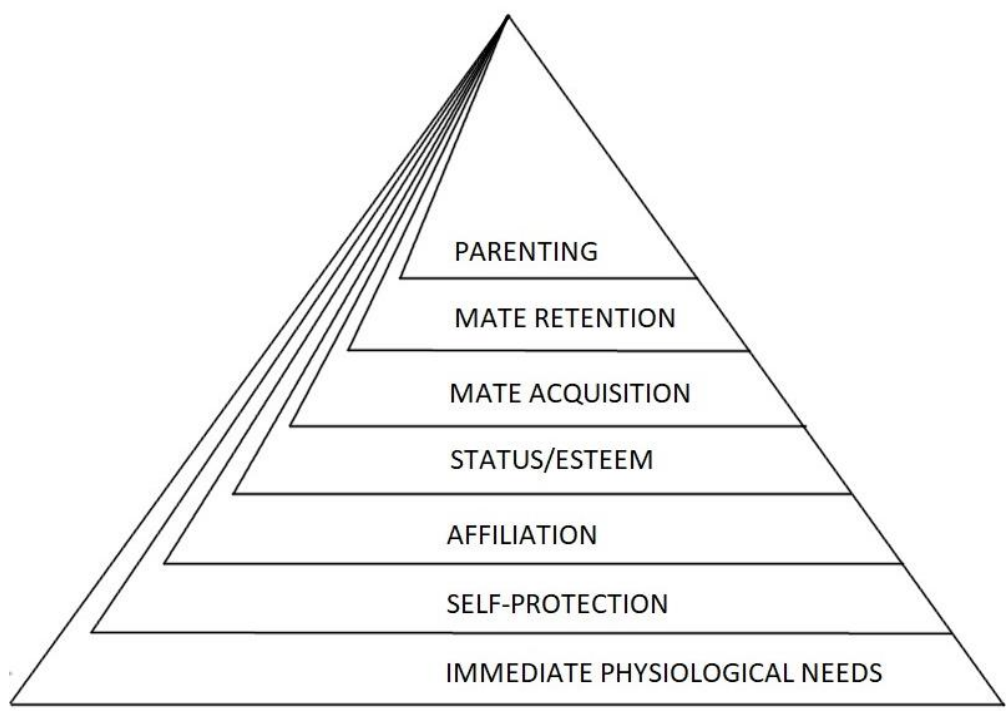

Figure 1. Hierarchical model of fundamental social motives (see Kenrick et al., 2010).

For example, the mate attraction motive is associated with lower loss aversion in men: in an experiment, they were more willing to donate to charity when observed by potential mating partners (Iredale, van Vugt, \& Dunbar, 2008), and they were found to be willing to bear greater financial and physical risks when motivated to look for mating partners (Baker \& Manner, 2009). In another study, the activation of the self-protection motive led the subjects to misinterpret emotional expressions. They perceived anger on the faces of members of a different ethnic group (out-group members), which were in fact expressionless (Kenrick et al., 2010). One of the important assumptions of the fundamental motives theory is that particular motivations are domain-specific. This means that people's objectives in different contexts and particularly in different social situations are different. The perception and evaluation of reality is subordinated to these objectives, and they are different for different relationships (strangers, relatives, potential partners, etc.). According to the concept of domain-specific motives, the experience of thoughts and emotions depends on what evolutionary dilemmas are involved in with particular social relations (Kenrick, Neuberg, \& Cialdini, 2015).

The concept of fundamental social motives has been operationalized in the form of the Fundamental Social Motives Inventory (FSMI; Neel, Kenrick, White, $\&$ Neuberg, 2016), which has been translated and adapted into Polish (Kozłowska \& Lachowicz-Tabaczek, unpublished material). The original inventory com- 
prises eleven scales, because three out of seven motives distinguished by the theory have a multifactorial structure. The affiliation motive turned out to have a three-factor structure, while both the kin care motive and the mate retention motive proved to have a two-factor structure. FSMI scales are: Self-Protection, Disease Avoidance, Affiliation (Group Relationships, Fear of Rejection, Independence), Status, Mate Attraction, Mate Retention (general motive for maintaining relationships with a partner and breakup concern) and Kin Care (care towards relatives and own children). The combined measurement of all social motives using a reliable and valid tool enables researchers to analyze individual differences in this area.

In the study by Neel and colleagues (2016), fundamental social motives correlated significantly with numerous life experiences and behaviors. The authors underline that, despite the ongoing progress of research on fundamental social motives, many issues remain unresolved. They encourage researchers to study the determinants of fundamental social motives and their relationships to other variables such as individual or intergenerational differences as well as to perform longitudinal comparisons or analyses of strategies to achieve particular motives - to investigate whether people engage in activities aimed at increasing the chance of achieving the goal or whether they avoid behaviors that may end in failure.

The assumptions presented by Neel and colleagues (2016) show that the fundamental social motives model can constitute an abundant source of information about individual differences in motivation (Neel et al., 2016). Currently, there is no research investigating the links between fundamental social motives and self-esteem, which, according to evolutionary theories, can serve as a source of valuable information on the level of social acceptance or selection of partners for social interaction (Leary \& Baumeister, 2000; Leary, 2005; Kavanagh, Robins, \& Ellis, 2010).

According to the sociometer theory (Leary \& Baumeister, 2000), self-evaluation is an indicator of social acceptance-people are motivated to avoid rejection or exclusion, and using self-evaluation they are able to monitor the current level of social acceptance (Leary, Schreindorfer, \& Haupt, 1995). So far, self-esteem in the context of sociometer theory implies that people have a permanent and strong need to maintain interpersonal relationships (the need to belong; Baumeister \& Leary, 1995). This need has evolved because individuals living in groups, and with the support of group members, had a better chance of survival and protected their offspring more effectively (Baumeister \& Leary, 1995). The support received from others contributes significantly to mental and 
physical health (Cohen \& Wills, 1985). Many studies point to the negative consequences of interpersonal rejection in the form of emotional problems, difficulties in establishing relationships, or unsuitable attempts to gain acceptance (e.g., excessive dependence, participation in criminal groups), which are often accompanied by low self-esteem (Leary et al., 1995).

The sociometer hypothesis was significantly broadened within the evolutionary paradigm by Kirkpatrick and Ellis $(2001,2006)$. The theory suggests there are many sociometers which are linked to different systems that are responsible for behavior control - both in everyday situations and in far-reaching behavioral strategies. Sociometer is an important source of information that enables making adaptive decisions leading to the selection of interaction partners. In the context of building social relations in various domains (work, friendship, search for a sexual relationship partner), individuals face the challenge of an appropriate level of aspiration. Therefore, it is non-adaptive for an individual to invest in relations with persons whose subjective value in a given area is lower than their own. Striving to build a relationship with a higher value partner will involve a risk of losing resources. Kirkpatrick and Ellis (2001) argue that an important function of self-esteem is to guide social choices in such a way as to select interaction partners whose value is as high as possible while minimizing the risk of rejection. A postulate resulting from the Kirkpatrick and Ellis's model is that public acceptance and rejection provide information for domain-specific sociometers, resulting in the individual experiencing changes in the level of specific self-esteem in each domain. The aim of this process is to introduce changes in the level of aspirations when establishing social relations. Kirkpatrick and Ellis stress that domain-specific sociometers play a particularly important role in managing behavior and in personality development. However, they also recognize that domain-specific areas show structural links with global self-evaluation. They explain the relationship between domain-specific self-esteem and global self-esteem by pointing out that in many cases domain-specific self-evaluations are correlated with each other. According to Kirkpatrick and Ellis, self-esteem is not just a sociometer but consists of many sociometers corresponding to different areas of social functioning. It is worth noting the distinction between state self-esteem and trait self-esteem. Global self-evaluation as a sociometer described by Leary and Baumeister (see Kirkpatrick \& Ellis, 2001) - i.e., self-evaluation as a state-reflects the degree of social inclusion currently experienced by the individual. It is therefore an acceptance indicator. Self-esteem, on the other hand, defines a certain potential for being accepted, or the probability of being included in social relations. Trait self-esteem is therefore an indicator of the individu- 
al's level of acceptability. Also in this case, the authors suggest the existence of relationships between trait self-esteem and the individual's characteristics, which are related to his or her potential to build effective relationships and interact in specific areas (which means they are important for evolutionary success). Having desirable characteristics that facilitate forming romantic relations, building an alliance, or functioning high in the social hierarchy is an indicator of potential inclusion in these roles. These potentials (often correlated with each other) are reflected in the level of trait self-esteem.

One of the domain-specific sociometers that has been broadly investigated is the mating sociometer (Kavanagh et al., 2010; Kavangh, Fletcher, \& Ellis, 2014; Bale \& Archer, 2013). Its functioning can be described as follows: the repeated experience of rejection by potential romantic partners leads to a decrease in self-esteem. As a result, the person becomes less selective in his or her choice of potential partners. Similarly, experiencing interest and being adored strengthens self-esteem. This experience makes the individual raise their expectations and become more selective when deciding to establish a relationship with a potential partner. The concept of self-evaluation as a sociometer controlling the choice of partners for romantic relations helps explain data present in the literature by suggesting that individuals who perceive themselves as having high value in the matrimonial market often have exorbitant expectations in the process of partner selection (Kenrick, Groth, Trost, \& Sadalla 1993; Pawłowski \& Dunbar, 1999). A number of theories, such as the self-evaluation maintenance theory (Tesser, 1988) or the concept of contingent self-esteem (Crocker, Luhtanen, Cooper, \& Bouvrette, 2003), indicate that high self-esteem is linked to experiencing success, achieving a desirable social position, or physical attractiveness. It is worth noting that these characteristics also indicate reproductive capacity.

In addition to self-esteem level, this study investigated the dimension of self-esteem instability, defined as the individual variability of self-esteem level, originally assessed on the basis of multiple measurements of the currently experienced self-esteem. The standard deviation of these measurements was an indicator of the variable (Kernis, Grannemann, \& Barclay, 1989, 1992). Studies show that, compared to people with stable self-esteem, those with unstable self-esteem, have a lower level of self-awareness and less determination to pursue goals (Kernis et al., 2000); they focus on threatening and unpleasant aspects of interpersonal contact (Waschull \& Kernis, 1996) and react more strongly to everyday problems, overgeneralizing the negative implications of failures in specific areas (Kernis et al., 1989). Low stability of self-esteem and self-concept is combined with increased sensitivity to evaluative events, increased concern about how one 
perceives oneself and overreliance on social sources of evaluation (Kernis et al., 1989; Rosenberg, 1986; see Kernis et al., 1992). It therefore appears that unstable self-esteem may be linked to rejection sensitivity reflected in certain fundamental social motives.

In view of the above considerations, the aim of this study was to examine the relationship between the fundamental social motives and the level and stability of self-esteem. The relationship between social relations and self-esteem is documented both theoretically and empirically. However, the model of fundamental social motives allows for a detailed analysis of the needs in terms of forming domain-specific ties and affiliations. The aim of this study was to answer the question of whether there is a correlation between the intensity of motivation to build social relations and the dimensions of self-esteem. Social motives derived from the theory of sociometers (sociometer and mating sociometer) were chosen for the purpose of this study. The theoretical model adopted here included three subcales related to the affiliation motive (Striving to Maintain Group Relations, Fear of Rejection, and Independence) and two scales associated with the mate retention motive (Willingness to Maintain Relations With the Partner and Breakup Concern).

I expected that both the level of self-esteem and its instability would be linked to the motives of affiliation and the motives related to the relationship with the romantic partner. I formulated the following hypotheses:

(1) People with high scores on affiliation-group relations motivation will also have higher self-esteem than people scoring lower on that motive.

(2) Individuals with a high level of fear of rejection motives (affiliationfear of rejection, breakup concern) and the affiliation-independence motive will have lower self-esteem than those scoring low on these motives.

(3) Individuals scoring high on affiliation - fear of rejection, breakup concern, and affiliation - independence will have more unstable self-esteem than those scoring low on these motives.

Assuming that the individual level of fundamental social motives influences the perception and evaluation of reality (Kenrick et al., 2010), the question arises as to whether this pattern can also be reflected in self-evaluation and self-perception. The motives analyzed here are directly related to the areas relevant for the sociometer (Baumeister \& Leary, 1995; Kavanagh et al., 2010). But what they reflect is the need to form such relationships, not actual acceptance or rejection experienced. Regression analyses were carried out in which the level and instability of self-esteem were assumed to be explained variables, while affiliation motives (affiliation - group relations, affiliation - fear of rejection, affilia- 
tion-independence) and motives related to building romantic relations (mate attraction, mate retention, breakup concern) were explanatory variables. I formulated further hypotheses for these analyses:

(4) Motives related to the need to maintain relations (affiliation-group relations, mate retention) will predict self-esteem level.

(5) Motives related to fear of rejection (affiliation - fear of rejection, breakup concern) and the motive related to the lack of aspiration to maintain close relations (affiliation - independence) will predict self-esteem instability.

Due to the fact that both the concept of fundamental social motives and the concept of sociometer relate to the assumptions of evolutionary psychology, I decided to conduct separate regression analyses for women and men, formulating no hypotheses regarding the expected results in this case.

\section{METHOD}

\section{Participants and Test Procedure}

I distributed 100 sets of questionnaires to students of the University of Wrocław in order to obtain data using the snowball method; other 200 people provided data electronically via a research panel. At the same time, data from further 76 people were collected electronically via social networking sites. Of the questionnaires distributed on paper, 87 were returned fully completed and included in the calculations. Participation in the survey was voluntary and anonymous. People who were recruited via the research panel received points in a loyalty program. Due to different methods of obtaining data, the results from the Internet sample $(n=276)$ were compared with the results obtained from other respondents $(n=87)$ in terms of mean, standard deviation, skewness, and kurtosis. As the parameters of data distribution did not show any significant discrepancies, I carried out further analyses on both samples together $(N=363)$. In addition to measuring fundamental social motives and self-esteem dimensions, the study included demographic variables such as age and gender, as well as relationship status and having or not having children. The study subjects were 20 to 50 years old $(M=34, S D=8.05) ; 49 \%$ of them were women. The relationship status in the sample was as follows: $10.2 \%$ of the subjects defined themselves as lonely and not currently seeing anyone, $7.9 \%$ specified their status as lonely and looking for a partner, $29.7 \%$ of the respondents were in a permanent informal 
relationship, while $47.1 \%$ were married. The remaining $5.1 \%$ of the samples were divorced or widowed. $40.2 \%$ of the respondents had no children.

\section{MEASURES}

The following questionnaires were used in the study: the Fundamental Social Motives Inventory (FSMI) by Neel et al. (2016) as adapted into Polish by Kozłowska and Lachowicz-Tabaczek (unpublished), the Self Esteem Scale (SES) by Rosenberg, as adapted into Polish by Dzwonkowska, Lachowicz-Tabaczek, and Łaguna (2008), and two scales measuring self-esteem instability: the Stability of Self Scale (RSSS) by Rosenberg and the Labile Self-Esteem Scale (LSES) by Dykman - due to the lack of Polish versions of these two scales, I used an independent translation (see Webster et al., 2016), the content of which I consulted with a language specialist. The psychometric properties of these translations will be presented below.

The original FSMI consists of 66 items grouped into eleven scales (six items in each scale; Neel, Kenrick, White, \& Neuberg, 2016). The reliability of individual scales (Cronbach's $\alpha$ ) in the study by Neel and colleagues ranged from .75 to .95 . The Polish version of FSMI was developed in the process of adaptation by Kozłowska and Lachowicz-Tabaczek. The items of the original questionnaire were translated from English into Polish and back. The consistency of the Polish and English versions was analyzed. A group of 26 graduate English Studies students completed both language versions of the questionnaire. Correlations between the scales ranged from .55 (for the self-protection motive) to .99 (taking care of one's own children). The average correlation between the scales in the Polish and English versions was .82 (at $p<.05$ ). As a result of analyses aimed at determining divergent and convergent validity, the questionnaire was assessed as valid at a level similar to the English version. Additionally, I calculated Cronbach's $\alpha$ coefficients for all scales. The reliability of individual scales was high, with $\alpha=.80$ for self-protection (SPO), .79 for disease avoidance (DIS), .89 for affiliation-group relations (AFG), .86 for affiliation-exclusion concern (AFX), .90 for affiliation-independence (AFI), .71 for status (STA), .82 for mate attraction (MAT), .72 for mate retention (MTR), .90 for breakup concern (MTB), .73 for kin care - family members (KCF); and .80 for kin care - children (KCC). Each item phrased as a statement is evaluated on a Likert scale from 1 (strongly disagree) to 7 (strongly agree). Example items are as follows: "I think a lot about how to stay safe from dangerous people" (Self-Protection 
scale); "I avoid places and people that may carry diseases" (Disease Avoidance scale); "When I am in a group, I do things to help the group stay together" (Affiliation-Group Relations scale); "It would be a big deal for me if a group excluded me" (Fear of Rejection scale); "I would prefer to spend time alone than to be surrounded by other people" (Affiliation-Independence scale); status: "It is important for me that other people look up to me" (Status scale); "I spend a lot of time thinking about ways to meet possible dating partners" (Mate Attraction scale); "It is important to me that my partner is emotionally loyal to me" (Mate Retention scale); "I often think about whether my partner would leave me" (Breakup Concern scale); "Caring for family members is important to me" (Kin Care-Family Members scale); "Taking care of my children is not a high priority to me" (Kin Care-Children scale).

Morris Rosenberg's Self-Esteem Scale (SES) measures overall positive self-evaluation, understood as a trait. The questionnaire consists of ten statements (e.g., "I feel that I'm a person of worth, at least on an equal plane with others") assessed on a scale from 1 (I strongly agree) to 4 (I definitely disagree). Cronbach's $\alpha$ coefficient for the Polish version of the SES ranged from .81 to .83 (the results differed slightly in different groups; Laguna, Lachowicz-Tabaczek, \& Dzwonkowska, 2007; Dzwonkowska et al., 2008).

The Labile Self Esteem Scale (LSES) is used to measure self-reported perceived self-esteem instability (Dykman, 1998; see Webster et al., 2016). The reliability of the method is acceptable: the scale correlates with the level of self-esteem in such a way that people whose self-esteem is low have lower self-esteem stability as well. This regularity was observed in analyses using the classic method of measuring self-esteem stability with standard deviation and also with Dykman's LSES (deCremer \& Sedikides, 2005). Due to the lack of an official Polish adaptation of LSES, I used a translation of the scale (consulted with a proficient English speaker). Respondents respond to five statements on a scale from 1 (I strongly disagree) to 5 (I strongly agree). Example items are: "My self-esteem shifts rapidly from feeling good about myself on one day to feeling bad about myself the next day" or "I'm often feeling good about myself one minute, and down on myself the next minute." LSES items reflect the instability of opinions and beliefs about oneself, and therefore the scale can be described as measuring cognitive self-esteem instability. The reliability of the scale (Cronbach's $\alpha$ $=.87$ ) and the discriminatory power of the items turned out to be high, so the results obtained with this scale can be considered reliable.

The Rosenberg Stability of Self Scale (RSSS) is a one-dimensional self-report measure designed to assess the daily fluctuations of self-esteem level. 
RSSS scores reflect the instability of self-esteem (high scores indicate low self-esteem stability). RSSS is available in two versions: original and revised. The original version consists of both questions and statements. The revised version (the translation of which was used in this study) consists of five statements which respondents rate on a scale from 1 (I strongly disagree) to 5 (I strongly agree; Marsh, 1993; see Webster et al., 2016). Examples of RSSS items are as follows: "My opinion of myself tends to change a good deal instead of always remaining the same"; "I feel that nothing can change the opinion I currently hold of myself." Unlike in LSES, instability in this questionnaire concerns the emotional aspects of self-evaluation. The reliability of the scale measured as Cronbach's $\alpha(.75)$ and the discriminatory power of the items have proven to be acceptable.

\section{RESULTS}

\section{Descriptive Statistics and Correlations}

The analysis of Pearson's $r$ correlations between the variables revealed significant (at $p<.05)$ relations between self-esteem dimensions and social motives associated with building and maintaining relationships. These were the motives of affiliation, related to the relationship with a romantic partner and with family members.

Self-esteem level correlated positively with the affiliation-group relations motive, the mate retention motive (which is consistent with Hypothesis 1) and with motives related to caring for family members. Self-esteem level correlated negatively with motives related to fear of rejection (which is consistent with Hypothesis 2). Self-esteem instability did not correlate with the affiliationgroup relations motive. High scores on the affiliation - fear of rejection motive were associated with greater instability of self-esteem. Self-esteem instability correlated with the affiliation - independence, mate attraction, and breakup concern motives (as predicted in Hypothesis 3). In addition, it turned out that people motivated to gain status are also characterized by greater instability of self-esteem. This correlation is low and its occurrence has not been predicted. However, this observation may be used as a source of future hypotheses. Self-esteem instability showed a negative correlation with the following social motives: mate retention, kin care — family members, and kin care—children. 
Table 1. Descriptive Statistics, Reliability of Scales, and Correlations Between Variables

\begin{tabular}{|c|c|c|c|c|c|c|c|c|c|c|c|c|c|c|c|c|c|}
\hline & Mean & $S D$ & SPO & DIS & AFG & AFX & AIF & STA & MAT & MTR & МТВ & $\mathrm{KCF}$ & $\mathrm{KCC}$ & RSSS & LSES & SES & $\alpha$ \\
\hline SPO & 4.43 & 0.97 & 1.00 & & & & & & & & & & & & & & .74 \\
\hline DIS & 4.04 & 0.99 & $.44^{*}$ & 1.00 & & & & & & & & & & & & & .67 \\
\hline AFG & 4.57 & 0.95 & $.14 *$ & $-.16^{*}$ & 1.00 & & & & & & & & & & & & .81 \\
\hline AFX & 4.16 & 1.11 & $.33 *$ & $.14 *$ & $.38 *$ & 1.00 & & & & & & & & & & & .83 \\
\hline AFI & 3.96 & 1.15 & $.15^{*}$ & $.10 *$ & $-.30 *$ & .10 & 1.00 & & & & & & & & & & .85 \\
\hline STA & 4.35 & 0.80 & $.30 *$ & $.22 *$ & $.39 *$ & $.47^{*}$ & .02 & 1.00 & & & & & & & & & .62 \\
\hline MAT & 3.11 & 1.44 & .04 & .04 & -.08 & $.19 *$ & .06 & .08 & 1.00 & & & & & & & & .82 \\
\hline $\mathrm{MTR}^{1}$ & 5.50 & 1.15 & .06 & .09 & $.20 *$ & $-.14 *$ & $-.30 *$ & .03 & $-.59^{*}$ & 1.00 & & & & & & & .64 \\
\hline MTB $^{1}$ & 3.38 & 1.53 & $.19 *$ & .05 & -.03 & $.45^{*}$ & $.24 *$ & $.13^{*}$ & $.26^{*}$ & $-.24^{*}$ & 1.00 & & & & & & .92 \\
\hline $\mathrm{KCF}$ & 5.26 & 1.05 & .06 & -.09 & $.40 *$ & .01 & $-.40 *$ & $.14 *$ & $-.28^{*}$ & $.52 *$ & $-.21 *$ & 1.00 & & & & & .79 \\
\hline $\mathrm{KCC}^{2}$ & 5.24 & 1.00 & $.15^{*}$ & -.13 & $.21 *$ & -.08 & $-.15^{*}$ & .04 & $-.18^{*}$ & $.36^{*}$ & -.09 & $.42 *$ & 1.00 & & & & .57 \\
\hline RSSS & 2.72 & 0.78 & .06 & .09 & -.07 & $.40^{*}$ & $.27^{*}$ & $.13^{*}$ & $.26^{*}$ & $-.33^{*}$ & $.42 *$ & $-.26^{*}$ & $-.22 *$ & 1.00 & & & .75 \\
\hline LSES & 2.64 & 0.91 & $.13 *$ & .08 & -.10 & $.46^{*}$ & $.27^{*}$ & $.13 *$ & $.29 *$ & $-.32 *$ & $.47 *$ & $-.24 \%$ & $-.18^{*}$ & $.85^{*}$ & 1.00 & & .87 \\
\hline SES & 2.83 & 0.53 & -.04 & -.04 & $.26 *$ & $-.33^{*}$ & $-.29 *$ & .07 & $-.23^{*}$ & $.25^{*}$ & $-.45 *$ & $.29 *$ & $.25^{*}$ & $-.57^{*}$ & $-.61 *$ & 1.00 & .87 \\
\hline
\end{tabular}

Note. SOP — self-protection; DIS — disease avoidance; AFG — affiliation — group relations; AFX — affiliationfear of rejection; AFI — affiliation — independence; STA — status; MAT — mate attraction; MTR — mate retention; MTB-breakup concern; KCF-kin care-relatives; KCC — kin care-children; RSSS-Rosenberg's self-esteem stability; LSES-Dykman's self-esteem stability; SES—-self-esteem level; * $p<.05,{ }^{1} n=280,{ }^{2} n=199$.

\section{Regression Analysis}

Social motives theoretically relevant form the perspective of sociometer theories (sociometer and mating sociometer) showed links with the level and instability of self-esteem. In order to deepen the analyses of the quantitative relationships between social motives and the dimensions of self-esteem, I carried out a multiple regression analysis. Due to slight correlations between some predictors, I performed an analysis of their collinearity, as shown in Table 2.

Table 2. Explanatory Variables' Collinearity Analysis

\begin{tabular}{ccccccccc}
\hline & Coefficients & $S E$ & $t$ & $p$-value & \multicolumn{2}{c}{$95 \%$ CI } & $S D$ & VIF \\
\hline AFG & .18 & .03 & 5.40 & .00 & .12 & .25 & 0.95 & 1.48 \\
AFX & -.16 & .03 & -5.26 & .00 & -.22 & -.10 & 1.11 & 1.72 \\
AFI & -.06 & .03 & -2.18 & .03 & -.11 & -.01 & 1.15 & 1.41 \\
MAT & -.04 & .03 & -1.55 & .12 & -.10 & .01 & 1.44 & 2.28 \\
MTR & .00 & .03 & -0.13 & .89 & -.06 & .06 & 1.15 & 1.75 \\
MTB & -.08 & .02 & -4.11 & .00 & -.12 & -.04 & 1.53 & 1.41 \\
\hline
\end{tabular}

Note. AFG—affiliation — group relations; AFX — affiliation — fear of rejection; AFI—affiliation—independence; MAT - mate attraction; MTR - mate retention; MTB — breakup concern. 
Since the VIF indices for individual variables range from 1.41 to 2.28 , all variables from the model were taken into account in the regression analysis.

The theoretical model turned out to be significant, $F(6,27)=24.67$ $(p<.001)$, and the explanatory variables accounted for a total of $35 \%$ of the variance in the dependent variable $\left(R^{2}=.35\right)$. Detailed data calculated separately for two gender groups are shown in Table 3. For men, the affiliation-group relations and affiliation - fear of rejection motives were important predictors of self-esteem level. For women, the predictors were: affiliation-group relations, affiliation - fear of rejection, affiliation - independence, and breakup concern. These results are only partially consistent with Hypothesis 4.

The regression analysis for self-esteem instability was carried out separately for the results obtained with LSES and with RSSS. This was done in order to determine whether the two measures should be treated interchangeably or whether the emotional and cognitive nature of the measured instability of self-esteem reflects qualitatively different aspects of the phenomenon.

Table 3. Regression Analysis Predicting the Level of Self-Esteem Measured by Rosenberg's SES From Fundamental Social Motives

\begin{tabular}{|c|c|c|c|c|c|c|}
\hline & $b^{*}$ & $b^{*}$ & $\beta$ & \multirow{2}{*}{\multicolumn{2}{|c|}{$\beta$}} & $p$ \\
\hline & \multicolumn{4}{|c|}{ Men $t(125)$} & & \\
\hline & \multicolumn{6}{|c|}{$R=.59, R^{2}=.35$, corrected $R^{2}=.325, F(6,125)=11.216, p<.001, S E=0.42$} \\
\hline & & & 3.12 & 0.46 & 6.76 & .00 \\
\hline AFX & -0.38 & 0.10 & -0.20 & 0.05 & -3.99 & .00 \\
\hline AFG & 0.38 & 0.09 & 0.21 & 0.05 & 4.04 & .00 \\
\hline AFI & -0.06 & 0.09 & -0.03 & 0.04 & -0.69 & .49 \\
\hline MAT & -0.12 & 0.09 & -0.05 & 0.04 & -1.34 & .18 \\
\hline MTR & 0.03 & 0.10 & 0.01 & 0.04 & 0.30 & .77 \\
\hline \multirow[t]{4}{*}{ MTB } & -0.14 & 0.09 & -0.05 & 0.03 & -1.56 & .12 \\
\hline & \multicolumn{6}{|c|}{ Women $t(140)$} \\
\hline & \multicolumn{6}{|c|}{$R=.61, R^{2}=.37$, corrected $R^{2}=.34, F(6,140)=13.52, p<.001, S E=0.46$} \\
\hline & & & 3.39 & 0.43 & 7.94 & .00 \\
\hline AFX & -0.28 & 0.08 & -0.14 & 0.04 & -3.37 & .00 \\
\hline AFG & 0.30 & 0.08 & 0.18 & 0.05 & 3.88 & .00 \\
\hline AFI & -0.17 & 0.07 & -0.09 & 0.04 & -2.27 & .02 \\
\hline MAT & -0.09 & 0.09 & -0.04 & 0.04 & -0.99 & .33 \\
\hline MTR & -0.02 & 0.09 & -0.01 & 0.04 & -0.22 & .83 \\
\hline MTB & -0.29 & 0.08 & -0.10 & 0.03 & -3.63 & .00 \\
\hline
\end{tabular}

Note. AFG—affiliation—group relations; AFX — affiliation — fear of rejection; AFI—affiliation—independence; MAT - mate attraction; MTR - mate retention; MTB - breakup concern. 
In the case of self-esteem instability measured with RSSS, the social motives that turned out to be significant predictors in the male group were affiliationfear of rejection and breakup concern, and the significant predictors in the female group were affiliation - fear of rejection and affiliation-independence. The obtained result is consistent with Hypothesis 5.

Table 4. Regression Analysis Predicting the Instability of the Self-Esteem Measured by Rosenberg's RSSS From Fundamental Social Motives

\begin{tabular}{|c|c|c|c|c|c|c|}
\hline & \multirow[b]{2}{*}{$b^{*}$} & \multicolumn{2}{|l|}{$S E$} & \multicolumn{3}{|l|}{$S E$} \\
\hline & & $b^{*}$ & $\beta$ & $\beta$ & $t$ & $p$ \\
\hline & \multicolumn{6}{|c|}{ Men $t(125)$} \\
\hline & \multicolumn{6}{|c|}{$R=.63, R^{2}=.39$, corrected $R^{2}=.36, F(6,125)=13.298, p<.001, S E=0.64$} \\
\hline & & & 1.69 & 0.70 & 2.43 & .02 \\
\hline AFX & 0.32 & 0.09 & 0.26 & 0.08 & 3.41 & .00 \\
\hline AFG & -0.15 & 0.09 & -0.13 & 0.08 & -1.65 & .10 \\
\hline AFI & 0.09 & 0.08 & 0.07 & 0.06 & 1.09 & .28 \\
\hline MAT & 0.04 & 0.09 & 0.03 & 0.06 & 0.44 & .66 \\
\hline MTR & -0.11 & 0.10 & -0.08 & 0.07 & -1.13 & .26 \\
\hline \multirow[t]{4}{*}{ MTB } & 0.29 & 0.09 & 0.17 & 0.05 & 3.29 & .00 \\
\hline & \multirow{2}{*}{\multicolumn{6}{|c|}{$\begin{array}{l}\text { Women } t(140) \\
R=.58, R^{2}=.34 \text { corrected, } R^{2}=.31, F(6,140)=11.766, p<.001, S E=0.66\end{array}$}} \\
\hline & & & & & & \\
\hline & & & 1.93 & 0.61 & 3.15 & .00 \\
\hline AFX & 0.35 & 0.09 & 0.24 & 0.06 & 4.03 & .00 \\
\hline AFG & -0.16 & 0.08 & -0.13 & 0.07 & -1.97 & .05 \\
\hline AFI & 0.25 & 0.08 & 0.18 & 0.06 & 3.29 & .00 \\
\hline MAT & 0.04 & 0.09 & & 0.06 & & .67 \\
\hline MTR & -0.13 & 0.09 & -0.09 & 0.06 & -1.43 & .16 \\
\hline MTB & 0.12 & 0.08 & 0.05 & 0.04 & 1.43 & .15 \\
\hline
\end{tabular}

Note. AFG — affiliation — group relations; AFX — affiliation — fear of rejection; AFI — affiliation —independence; MAT — mate attraction; MTR — mate retention; MTB — breakup concern.

Estimates made for the instability of self-esteem measured with the LSES showed the model to be significant, $F(6,27)=32.87(p<.001)$, explaining $42 \%$ of the variance in self-esteem instability. Detailed analyses carried out separately for women and for men revealed the following regularities. Self-esteem instability in men was higher when they also scored high on affiliation - fear of rejection and breakup concern. Self-esteem instability was lower when they scored high on affiliation - group relations. In women, the higher the scores on affiliationfear of rejection and affiliation-independence, the higher the self-esteem insta- 
bility. Self-esteem instability was lower when women scored high on affiliation-group relations. The link between self-esteem instability and the affiliation-group relations motive was not hypothesized. The remaining results are consistent with Hypothesis 5.

Table 5. Regression Analysis Predicting Self-Esteem Instability Measured by Dykman's LSES From Fundamental Social Motives

\begin{tabular}{|c|c|c|c|c|c|c|}
\hline & $b^{*}$ & $b^{*}$ & $\beta$ & $\beta$ & $t$ & $p$ \\
\hline & \multicolumn{6}{|c|}{$\operatorname{Men} t(125)$} \\
\hline & \multicolumn{6}{|c|}{$R=.66, R^{2}=.43$, corrected $R^{2}=.40, F(6,125)=15.729, p<.001, S E=0.69$} \\
\hline & & & 1.23 & 0.76 & 1.62 & .11 \\
\hline AFX & $\mathbf{0 . 3 4}$ & 0.09 & 0.31 & 0.08 & 3.80 & .00 \\
\hline AFG & -0.18 & 0.09 & -0.18 & 0.09 & -2.09 & .04 \\
\hline AFI & 0.04 & 0.08 & 0.03 & 0.07 & 0.51 & .61 \\
\hline MAT & 0.16 & 0.09 & 0.12 & 0.07 & 1.82 & .07 \\
\hline MTR & -0.07 & 0.09 & -0.06 & 0.07 & -0.78 & .43 \\
\hline \multirow[t]{4}{*}{ МТВ } & $\mathbf{0 . 3 0}$ & 0.08 & $\mathbf{0 . 2 0}$ & 0.06 & 3.49 & .00 \\
\hline & \multicolumn{6}{|c|}{ Women $t(140)$} \\
\hline & \multicolumn{6}{|c|}{$R=.66, R^{2}=.44$, corrected $R^{2}=.42, F(6,140)=18.403, p<.001, S E=0.69$} \\
\hline & & & 1.00 & 0.65 & 1.55 & .12 \\
\hline AFX & 0.50 & 0.08 & 0.39 & 0.06 & 6.31 & .00 \\
\hline $\mathrm{AFG}$ & -0.18 & 0.07 & -0.18 & 0.07 & -2.53 & .01 \\
\hline AFI & 0.21 & 0.07 & 0.18 & 0.06 & 3.09 & .00 \\
\hline MAT & 0.12 & 0.08 & 0.09 & 0.06 & 1.43 & .15 \\
\hline MTR & -0.05 & 0.08 & -0.04 & 0.07 & -0.54 & .59 \\
\hline МТВ & 0.11 & 0.07 & 0.06 & 0.04 & 1.50 & .14 \\
\hline
\end{tabular}

Note. AFG—affiliation—group relations; AFX—affiliation—fear of rejection; AFI—affiliation—independence; MAT—mate attraction; MTR — mate retention; MTB—breakup concern.

Due to the fact that correlation analysis revealed relations between self-esteem dimensions and motives associated with the relationship with relatives, these motives were included as predictors in an additional regression analysis, performed for exploratory purposes. Their inclusion did not significantly affect the model's fit. Kin care-family and kin care-children were not significant predictors of self-esteem level or self-esteem instability. It should be noted that after the inclusion of the kin care motive in the model, the calculations were based on a smaller sample $(n=146)$. 


\section{DISCUSSION}

The analysis shows that there are correlations between the level and stability of self-esteem and fundamental social motives in the domains of affiliation and relations with a romantic partner. Additionally, the dimensions of self-esteem correlated with the motives associated with caring for relatives. The results of regression analyses showed a special role of affiliation motives and breakup concern as predictors of the level and instability of self-esteem. Separate gender analyses point to a number of interesting findings.

The main effect revealed by the analyses is that self-esteem level and self-esteem instability are influenced by different sets of motives. The affiliationGroup Relations motive is a predictor of self-esteem level. Being part of a group, caring for the group's unity, and communicating with people is conducive to increasing self-esteem. Decrease in self-esteem stability is more strongly associated with the affiliation - fear of rejection motive. Fear of rejection turned out to predict changes in both the level and stability of self-esteem. These effects were independent of gender.

Another conclusion is that there are differences between women and men regarding relations between self-esteem dimensions and fundamental social motives (in particular, with regard to breakup concern). In the case of women, this motive proved to be an important predictor of self-esteem level: women who showed a higher level of breakup concern were characterized by a lower level of self-esteem than women who scored low on this scale. For men, on the other hand, increased concerns about their current relationship durability were associated with lower self-esteem stability compared to men who did not display a motive stemming from such anxiety. The breakup concern motive was the second strongest predictor of self-esteem instability (measured with both questionnaires) in men, but it was not a predictor of their self-esteem level. This may be due to the fact that women and men react differently to relationship breakdown (Rosenfeld, 2017), and therefore it is possibly also true for romantic relationships. The finding might suggest that, for women, the lack of security in relations may be a factor that unambiguously lowers their self-evaluation as a person, whereas in the case of men it is rather a factor that causes fluctuations in this respect. Potential explanations may be related both to the differences that women and men may show in interpreting rejection signals (women are better at reading emotional expressions, in particular subtle ones; Babchuk, Hames, \& Thompson, 1985; Hoffmann, Kessler, Eppel, Rukavina, \& Traue, 2010) as well as to the causal/community orientation and the role of interpersonal relations in women's 
and men's self-concept (Helgeson, 1994; Wojciszke \& Szlendak, 2010). Another difference that was revealed by separate gender analyses is the link of the affiliation-independence motive to self-esteem dimensions. This motive was a weak but statistically significant predictor of both the level and instability of self-esteem in women. In the female subjects higher scores on the affiliationindependence motive were associated with lower self-esteem level and lower self-esteem stability. In the case of men, this motive turned out not to be significant. Affiliation-independence is an individual's willingness to spend time alone, even at the cost of weakening relationships with other people. This result seems to be consistent with the existing research on gender differences in building social relations-women's support networks are more extensive; the relationship between welfare and social support is also stronger in women than in men (Antonucci \& Akiyama, 1987; Walen \& Lachman, 2000). Therefore, low motivation to build relationships or seek out support (manifested by the affiliationindependence motive sores) has a stronger impact on self-esteem in women than in men.

The Labile Self Esteem Scale and the Rosenberg Stability of Self Scale are meant to measure self-esteem instability, but their items differ in that they concern the cognitive vs. emotional aspects of self-regard, respectively. Firstly, the differences revealed here between these two methods of measurement concerned the level of the regression indices. Additionally, instability in the dimension of opinions and beliefs about oneself (measured by LSES) turned out to be related to the affiliation-group relations motive (both in women and in men), while instability in the dimension of feelings (measured by the RSSS questionnaire) was not affected by this motive. Therefore, among the respondents for whom being part of a group was important and who cared about unity and cooperation when they were part of a group, self-esteem was more stable, but only in the cognitive dimension. It is possible that people with a stronger group identity have a more stable self-esteem in the cognitive dimension, because the cognitive schema describing the group they identify with is less malleable (stereotype resistance to modification; Hilton \& von Hippel, 1996) than the self-concept (at least when it comes to the cognitive accessibility of certain aspects). Self-knowledge is multifaceted and complex (Kihlstrom, 2012), and individuals' level of awareness of their own characteristics and properties is influenced by experiences activating certain contents (Markus \& Wurf, 1987). However, it cannot be ruled out that these differences may constitute an artifact resulting, for example, from differences between the reliability of the two methods. 
As with every study, methodological limitations should be considered. First, regression analyses were performed jointly for affiliation motives and relationships with a partner in order to determine the role of these motives and their status as sociometers (sociometer and mating sociometer). This means that data was gathered from people who were currently in a relationship (formal or informal) with a romantic partner. The kin care motive is measured with this method exclusively in people who have children. However, it cannot be ruled out that the functioning of lonely and childless people may also be affected by unmet needs in this respect (or by the lack of demonstration of such needs). Nevertheless, the FSMI does not allow for such measurement. Obtaining a complete picture of the relationship between fundamental social motives linked to the need to belong (affiliation, relations with the partner, relations with family members) and self-esteem, which would allow us to generalize results, requires additional research. Furthermore, data was mainly collected through an online survey. A replication of the study with a similar sample using the pencil-and-paper method should be carried out. Another limitation is the fact that the instability of self-esteem was measured by with versions of methods not adapted to the Polish context (although the results gathered met cursory validity and reliability expectations).

Considering the above, it should be stressed that the undoubted advantage of the present study is its pioneering character in Poland (it has been the first one to use the FSMI). This study complements the existing research related to Baumeister's and Leary's concepts of sociometer and mating sociometer, indicating that the relationship between the dimensions of self-esteem and social relations goes beyond the sphere of actual experience and the support/acceptance currently received. This link has been observed in this study between motivation to build social relationships (in relation to both the need to build relationships and fear of rejection) and self-esteem measured as a trait (which may indicate an individual's level of acceptability; Kirkpatrick \& Ellis, 2001).

\section{REFERENCES}

Antonucci, C., \& Akiyama, H. (1987). An examination of sex differences in social support among older men and women. Sex Roles, 17(11-12), 737-749.

Babchuk, W. A., Hames, R. B., \& Thompson, R. A. (1985). Sex differences in the recognition of infant facial expressions of emotion: The primary caretaker hypothesis. Ethology and Sociobiology, 6, 89-101.

Baker, M. J., \& Maner, J. K. (2008). Risk-taking as a situationally sensitive male mating strategy. Evolution and Human Behavior, 29, 391-395. 
Bale, C., \& Archer, J. (2013). Self-perceived attractiveness, romantic desirability and self-esteem: A mating sociometer perspective. Evolutionary Psychology, 11(1), 68-84.

Baumeister, R., \& Leary, M. R. (1995). The need to belong: Desire for interpersonal attachments as a fundamental human motivation. Psychological Bulletin, 117(3), 497-529.

Beall, A. T., \& Tracy, J. L. (2017). Emotivational psychology: How distinct emotions facilitate fundamental motives. Social and Personality Psychology Compass, 11, e12303

Cohen, S., \& Wills, T. A. (1985). Stress, social support and the buffering hypothesis. Psychological Bulletin, 98, 310-357.

Crocker, J., \& Luhtanen, R. K., Cooper, M. L., \& Bouvrette, A. (2003). Contingencies of self-worth in college students: Theory and measurement. Journal of Personality and Social Psychology, 85(5), 894-908.

DeCremer, D, \& Sedikides, C. (2005). Self-uncertainty and responsiveness to procedural justice. Journal of Experimental Psychology, 41, 157-173.

Dzwonkowska, I., Lachowicz-Tabaczek, K., \& Łaguna, M. (2008). Samoocena i jej pomiar. Polska adaptacja skali SES M. Rosenberga. Podręcznik [Self-esteem and its measurement. Polish adaptation of M. Rosenberg's SES: A manual]. Psychological Test Laboratory of the Polish Psychological Association.

Helgeson, V. S. (1994). Relation of agency and communion to well-being: Evidence and potential explanations. Psychological Bulletin, 116, 412-428

Hilton, J. L., \& von Hippel, W. (1996). Stereotypes. Annual Review of Psychology, 47(250), 237-271.

Hoffmann, H., Kessler, H., Eppel, T., Rukavina, S., \& Traue, H. C. (2010). Expression intensity, gender and facial emotion recognition: Women recognize only subtle facial emotions better than men. Acta Psychologica, 135, 278-283.

Iredale, W., Van Vugt, M., \& Dunbar, R. (2008). Showing off in humans: Male generosity as a mating signal. Evolutionary Psychology, 6, 386-392.

Kavanagh, P. S., Fletcher, G. J., \& Ellis, B. J. (2014). The mating sociometer and attractive others: A double-edged sword in romantic relationships. Journal of Social Psychology, 154(2), 126-141.

Kavanagh, P. S., Robins, C. S., \& Ellis, B. J. (2010). The mating sociometer: A regulatory mechanism for mating aspirations. Journal of Personality and Social Psychology, 99(1), 120-132.

Kenrick, D. T, Griskevicius, V., Neuberg, S. L., \& Schaller M. (2010). Renovating the pyramid of needs: Contemporary extensions. Perspectives on Psychological Science, 5(3), 292-314.

Kenrick, D. T., Groth, G. E., Trost, M. R., \& Sadalla, E. K. (1993). Integrating evolutionary and social exchange perspectives on relationships: Effects of gender, self-appraisal, and involvement level on mate selection criteria. Journal of Personality and Social Psychology, 64, 951-969.

Kenrick, D. T., Neuberg, S. L., \& Cialdini, R. B. (2015). Social psychology. Goals in interaction. Boston, MA, US: Prentice Hall.

Kenrick, D. T., Neuberg, S. L., Griskevicius, V., Becker D. V., \& Schaller M. (2010). Goal-driven cognition and functional behavior: The fundamental motives framework. Current Directions in Psychological Science, 19(1), 63-67.

Kernis, M. H., Grannemann, B., \& Barclay, L. (1989). Stability and level of self-esteem as predictors of anger arousal and hostility. Journal of Personality and Social Psychology, 56(6), 1013-1022.

Kernis, M. H., Grannemann, B. D., \& Barclay, L. C. (1992). Stability of self-esteem: Assessment, correlates and excuse making. Journal of Personality, 60(3), 621-644.

Kernis, M. H., Paradise, A. W., Whitaker, D. J., Wheatman, S. R., \& Goldman, B. N. (2000). Master of one's psychological domain? Not likely if one's self-esteem is unstable. Personality and Social Psychology Bulletin, 26(10), 1297-1305. 
Kihlstrom, J. F. (2012). Searching for the self in mind and brain. Social Cognition, 30(4), 367-379

Kirkpatrick, L. A., \& Ellis, B. J. (2001). An evolutionary-psychological approach to self-esteem: Multiple domains and multiple functions. In G. J. O. Fletcher \& M. S. Clark (Eds.), Blackwell handbook of social psychology: Interpersonal processes (pp. 411-436). Oxford, United Kingdom: Blackwell.

Kirkpatrick, L. A., \& Ellis, B. J. (2006). The adaptive functions of self. Evaluative psychological mechanisms. In M. H. Kernis (Eds.), Self-esteem issues and answers: A sourcebook of current perspectives (pp. 334-339). New York, NY, US: Psychology Press.

Kozłowska, M., \& Lachowicz-Tabaczek, K. (2018). Polish version of the Fundamental Social Motives Inventory: Development and psychometric properties. Unpublished material.

Leary, M. R. (2005). Sociometer theory and the pursuit of relational value: Getting to the root of self-esteem. European Review of Social Psychology, 16(1), 75-111.

Leary, M. R., \& Baumeister, R. F. (2000). The nature and function of self-esteem: Sociometer theory. In M. P. Zanna (Eds.), Advances in experimental social psychology (vol. 32, pp. 1-62). San Diego, CA, US: Academic Press.

Leary, M. R., Schreindorfer, L. S., \& Haupt, A. L. (1995). The role of self-esteem in emotional and behavioral problems: Why is low self-esteem dysfunctional? Journal of Social and Clinical Psychology, 14, 297-314.

Łaguna, M., Lachowicz-Tabaczek, K., \& Dzwonkowska, I. (2007). Skala samooceny SES Morrisa Rosenberga - polska adaptacja metody [SES Morris Rosenberg's self-esteem scale: Polish adaptation of the method]. Psychologia Spoleczna, 2(4), tom 2, 164-176.

Markus, H., \& Wurf, E. (1987). The dynamic self-concept: Social psychological perspective. Annual Review of Psychology, 38, 299-337.

Neel, R., Kenrick, D. T., White A. E., \& Neuberg, S. L. (2016). Individual differences in fundamental social motives, Journal of Personality and Social Psychology, 110(6), 887-907.

Pawłowski, B., \& Dunbar, R. (1999). Impact of market value on human mate choice decisions. Proceedings of the Royal Society in London, Series B, 266(1416), 281-285.

Rosenfeld, M. (2017). Who wants the breakup? Gender and breakup in heterosexual couples. In D. F. Alwin, D. Felmlee, \& D. Kreager (Eds.), Social networks and the life course: Integrating the development of human lives and social relational networks (pp. 221-243). New York, NY, US: Springer.

Tesser, A. (1988). Towards a self-evaluation maintenance model of social behavior. Advances in Experimental Social Psychology, 21, 181-227.

Walen, H. R., \& Lachman, M. E. (2000). Social support and strain from partner, family, and friends: Costs and benefits for men and women in adulthood. Journal of Social and Personal Relationships, 17(1), 5-30.

Waschull, S. B., \& Kernis, M. H. (1996). Level and stability of self-esteem as predictors of children's intrinsic motivation and reasons for anger. Personality and Social Psychology Bulletin, 22, 4-13.

Webster, G. D., Smith, C. V., Brunell, A. B., Paddock, E. L., \& Nezlek, J. B. (2016). Can Rosenberg's (1956) Stability of Self Scale capture within-person self-esteem variability? Meta-analytic validity and test-retest reliability. Journal of Research in Personality, 69, 156-169.

Wojciszke, B., \& Szlendak, M. A. (2010). Skale do pomiaru orientacji sprawczej i wspólnotowej [Scales for measuring the agentic and communal orientation]. Psychologia Spoleczna, 5, 1(13), 57-70. 